\title{
Spatio-temporal variation and sensitivity analysis of aerosol particulate matter during the COVID-19 phase-wise lockdowns in Indian cities
}

\author{
Ahamed Ibrahim S.N. ${ }^{1} \cdot$ Sri Shalini $S^{1} \cdot$ Ramachandran $A^{1}$ • Palanivelu $K^{1}$ (D)
}

Received: 4 September 2020 / Accepted: 4 October 2021 / Published online: 20 January 2022

(c) The Author(s), under exclusive licence to Springer Nature B.V. 2021

\begin{abstract}
At the pandemic of COVID-19, the movement of business and other non-essential activities were majorly restricted at the end of March 2020 in India and continued in different lockdown phases until June 2020. By categorically, studying sensitivity towards anthropogenic factors with other environmental implications in urban Indian cities during phasewise lockdown scenarios will pave the way for a refined Clean Air Programme (CAP). In this study, the aerosol particulate matter variations between the lockdown phases in both spatial and temporal scales have been explored along with cities exceeding national ambient air quality (NAAQ) standards covering different geographical regions of India for their air quality level. The results of the spatial pattern of Copernicus Atmosphere Monitoring System (CAMS) near-real-time data showed a negative change both in Aerosol Optical Depth (AOD) (-0.2 to 0.1) and black carbon AOD (bcAOD) (-0.9 to -0.75). The changes were evident in successive phases of lockdown with an overall AOD reduction of about 70-90\%. Southern urban cities showed a significant impact of mobile sources from temporal analysis than other cities. Principal Component Analysis (PCA) for effects of pollutants by anthropogenic factors (mobile and point source) and meteorological factors (wind speed, wind direction, solar radiation, relative humidity) revealed the two significant driving factors. PM reduction was about 50-70\%, predominantly due to anthropogenic factors. The factor analysis revealed the influence of meteorological factors between the major urban cities (Delhi, Kolkata, Mumbai, Chennai, Bengaluru, and Hyderabad). Cities that exceed NAAQ standard performed well during phase-wise lockdowns, exceptional to cities in Gangetic plain. This study helps to frame region-specific strategic action plans for the CAP.
\end{abstract}

Keywords Particulate matter · COVID-19 - Anthropogenic impact · Air Pollution · Meteorological factors $\cdot$ Principal component analysis $\cdot$ Lockdowns

Palanivelu K

kpvelu@annauniv.edu

1 Centre for Climate Change and Disaster Management, Department of Civil Engineering, College of Engineering, Guindy Campus, Anna University, Chennai 600025, India 


\section{Introduction}

Air pollution causes more than seven million premature deaths a year, according to WHO, and $29 \%$ of lung cancer deaths, $17 \%$ of acute lower respiratory infection, $24 \%$ of stroke, $43 \%$ of chronic obstructive pulmonary disease deaths, and $25 \%$ of ischemic heart disease deaths (Balakrishnan et al., 2019; Rodríguez-Urrego \& Rodríguez-Urrego, 2020; WHO, 2016). Particulate matter (PM2.5) is believed to be the most harmful pollutant to human health. Urban air pollution in the world's second-most populous country in India is causing a severe threat to the environment and people. This air pollution is due to rapid urbanization, industrialization, economic growth, and uncertain weather patterns. Hence, a compelling need is to improve air quality by implementing a CAP with a sustainable and improved lifestyle. Indian cities are considered one of the worst hits by the PM, and mortality due to the health impact of such pollutants is about 1 million. According to the World Air Quality Report, 2019, of the world's top 30 most polluted cities, 21 cities are located in India, where Ghaziabad ranked at No.1, Delhi at 5, followed by Noida, Gurugram, and Greater Noida at 9 (all are National Capital Region - NCR). Delhi, the capital city, leads the world's regional capital city ranking for the average annual PM2.5 concentration $(98.6 \mu \mathrm{g} /$ cm3). Also, several major urban Indian cities of Mumbai $(45.3 \mu \mathrm{g} / \mathrm{cm} 3)$, Kolkata $(59.8 \mu \mathrm{g} /$ cm3), Hyderabad (39.0 $\mu \mathrm{g} / \mathrm{cm} 3)$, Chennai $(34.6 \mu \mathrm{g} / \mathrm{cm} 3)$, and Bengaluru $(32.6 \mu \mathrm{g} / \mathrm{cm} 3)$ were having higher average annual PM2.5 concentrations (IQAir, 2019). Though several action plans and measures such as i) National Clean Air Programme (NCAP) in 2019 to reduce PM2.5 and PM10 air pollution in 102 cities by $20-30 \%$ by 2024 compared to 2017 levels, and ii) in July 2019, India additionally joined the UN's Climate \& Clean Air Coalition (CCAC) as the 65th member to work together with global leaders on air pollution solutions (Government of India, 2019), it's still a long way to achieve the targets. PM emission rate remains increased in several cities. Several policy changes brought in automobile sectors, including cleaner fuel Bharat VI, where BS 6 Engine in the new vehicles and abatement of vehicles older than 10-15 years. The north Indian cities are frequently affected compared to the southern regions by the PM due to unfavourable meteorological conditions, including less wind speed and relative humidity (Guo et al., 2017; Ravindra et al., 2019).

After the pandemic of Coronavirus 2019 (COVID-19), which first started at the yearend of December 2019 at Wuhan, Hubei province of China, it has raised intense attention within China and internationally (Wang et al., 2020a). Shortly, WHO reported it to be a public health emergency of international concern on January 31, 2020, and a pandemic on March 11, 2020 (WHO, 2020a). Since, then globally, there have been 17,660,523 confirmed cases of COVID-19, including 696,147 deaths as of August 8, 2020 (WHO, 2020b). The pandemic has resulted in the most significant number of shutdowns/lockdowns worldwide to prevent the further spread of COVID-19. Restrictions first began in China in January 2020, soon followed by other countries in East Asia, Europe, North America, Africa, etc. Worldwide, following other countries, India imposed a strict nationwide lockdown on March 25, 2020, when the cases rose to 87 without categorizing the spread rate within the state. This restriction includes travel, mass congregation, non-essential services/industries, tourism, etc., to contain the spread rate of COVID-19 (Bureau of Immigration, 2020).

Lockdown has different effects on social, economic, and surroundings. It was shown to positively impact the environment, which is evident from recent studies. NASA (National Aeronautics and Space Administration) and ESA (European Space Agency) indicate that pollution in some of the epicentres of COVID-19, such as Wuhan, Italy, Spain, and the 
USA, etc. have reduced up to 30\% (Muhammad et al., 2020). Worldwide, several studies have reported the lockdown due to COVID-19 and its impact on air quality on different aspects, including insignificant and significant contributions towards anthropogenic restriction. Few studies are based on the condition of the meteorological parameters that favour the increase in the PM concentration (Berman \& Ebisu, 2020; Cameletti, 2020; Dantas et al., 2020; Gautam, 2020).

Few studies have been carried out in India for air quality assessment during lockdown (Karuppasamy et al., 2020; Sarfraz et al., 2020; Singh \& Chauhan, 2020; Jain \& Sharma, 2020). Mahato et al. (2020) studied the air quality of Delhi, and Shehzad et al. (2020) studied Delhi and Mumbai, with a focus on Nitrogen Dioxide reduction. Sharma et al. (2020) studied the air quality from March 16 to April 14 from 2017 to 2020 in 22 cities. It shows that no studies have carried out in-depth analysis on the effects of different lockdown scenarios for aerosol impacts in India between pre-lockdown, lockdown phase I to phase IV, and unlock conditions (from March 1 to June 30, 2020) in comparison with previous years of that same period (2017-2019). Notably, no studies have highlighted the most polluted cities in India during lockdown conditions. The present study is the first of its kind, focussing on the above aspects. The main aim of the present study is to identify the impact of lockdown restriction under different phases on the aerosol PM in major and polluted cities due to COVID 19 pandemic in India with the following objectives

i. to spatially analyze the change in concentration of AOD, black carbon AOD and PM during lockdowns in India

ii. to measure the temporal changes of air pollutant concentrations (PM10, PM2.5, and $\mathrm{CO})$ in major urban cities

iii. to quantify the factors which impact the aerosol load dispersion during phase-wise lockdown using PCA and factor analysis

iv. to evaluate the lockdown impact in most polluted cities (non-attainment cities) of India

The two significant factors, Anthropogenic and Meteorological loading effect in the Pollutant concentration, are derived to find the sensitivity towards these factors using Principal Component Analysis and Factor Analysis. This sensitivity study will aid to understand the carrying capacity of the mobile source of the densely populated cities. Thus, the 42 action points of the National clean air programme will be prioritized based on the cities where the pollution is from mobile sources as a significant contributing factor. The selection of major cities in the study is according to the World Air Quality 2019. The key priority cities of India are Delhi, Mumbai, Kolkata, Chennai, Bangalore, Hyderabad, and covering various geographical regions of non-attainment cities. Furthermore, based on the outcome, the region-wise unique strategies can frame to address the CAP.

\section{Methodology}

The Spatio-temporal variations of the aerosol PM were studied using the following methods and models. The regional forecasting service, Copernicus Atmosphere Monitoring System (CAMS), estimated from 7 different chemistry models, which is calculated ensemble media were used for the analysis. Spatial gridded $(0.5 \times 0.5$-degree 
resolution) of Near-real-time atmospheric composition with the surface model was processed in the Copernicus Atmosphere Monitoring System portal (Benedetti et al., 2009; Morcrette et al., 2009) for selection of the Indian subcontinent. CAMS generated in Network Common Data Form (netCDF) was further analyzed the parameters Aerosol Optical Depth (AOD) and Black carbon aerosol optical depth at $550 \mathrm{~nm}$ (bcAOD) using climate data operators (CDO) (Schulzweida, 2019). The particulate matter PM10 and PM2.5 and other vehicular pollutants such as CO, SO2, and NOx with the weather parameters such as solar radiation (SR), wind speed (WS), wind direction (WD), and relative humidity $(\mathrm{RH})$ were studied for the following selected cities. The study included significant urban cities such as Delhi, Kolkata, Mumbai, Chennai, Bengaluru, and Hyderabad (key cities according to World Air Quality Report, 2019) (IQAir, 2019) and other most polluted non-attainment cities (declared by National Green Tribunal(NGT Order no 681, 2018) covering different geographical regions (plains, highlands, Deccan plateaus, hilly terrains, arid, semi-arid, coastal and non-coastal) of India. All the data was collected hourly from the Central Pollution Control Board (CPCB), the central control room for the air quality portal (https://app.cpcbccr.com/ccr/). Among the various Indian cities, only 39 major and non-attained cities data were available for further analysis. The data availability of previous years of the same period of different lockdown periods from 2017 to 2019 was considered as average period.

Along with the data available during the COVID-19 pandemic lockdown period (March 01 to June 30, 2020), as follows, were considered as the current period for the study. The National Green Tribunal of India has listed 122 cities exceeding the NAAQ standard (CEN) and has declared them to be the most polluted cities in the country. From the available data (38 cities) for CEN from CPCB, the change ratio from the historical average is calculated and studied based on the geographical nature of the cities to find the impact of the lockdowns on the ambient concentration level.

\subsection{Study period}

Although India has registered its first case in February, the nationwide complete restricted lockdown with minimal activities for essential has been implemented starting from March 25, 2020 (Ministry of Home Affairs, 2020). The study period chosen in different lockdown phases in India are:

- Pre-Lockdown: March 01 to March 24, 2020 (Consider as business as usual activities)

- Lockdown Phase I: March 25 to April 14, 2020 (Major Non-essential activities shut down)

- Lockdown Phase II: April 15 to May 03, 2020 (Continued the previous lockdown and significant policy changes have been framed for further lockdown)

- Lockdown Phase III: May 04 to May 17, 2020 (Categorized the regions based on the pandemic and restriction has been relaxed in the green and yellow zone)

- Lockdown Phase IV: May 18 to May 31, 2020 (Restriction further relaxed to the red zone area where the COVID-19 cases are relatively high)

- Unlock June 01 to June 30, 2020 (Intrastate non-essential activities and transport has been allowed in green and yellow zone-Unlock scenario initiated and given relaxed further towards normal economic activities) 
The selected cities values were averaged and processed for the temporal analysis using the R Programming Tool for statistics (RStudio Team, 2020) and it was analyzed using the open-air tool (Carslaw \& Ropkins, 2012).

The Change Ratio (CR) of pollutants was calculated using Eq. 1.

$$
\begin{aligned}
\mathrm{CR}= & (\text { Current ambient concentration }- \text { Average ambient concentration }) \\
& \text { /Average ambient concentration }
\end{aligned}
$$

where Current ambient concentration is considered the periods of lockdown in the current year, and Average ambient concentration is termed as the historical average ambient concentration level of pollutants and meteorological variables from 2017 to 2019. The CR is estimated for both spatial and temporal variations.

Correlations between the air pollutants with climate were performed using Pearson correlation jointly with hierarchical clustering. Factor analysis was adopted to simplify the influencing meteorological variables with ambient pollutants (Jolliffe, 1986). Linear regression analysis was used to relate the factors with different significant cities and lockdown phases.

\subsection{Principal component analysis (PCA)}

Principal Component Analysis is vital for framing policies since each decision must be supported by factual and scientific research. Hence, the order of the variables observed during lockdown is the most important factor because all the analysis is intercorrelated with time and seasons (Tobías et al., 2004). It is also a comprehensive tool to predict the directions in the observed pollution dataset. They have the highest variability through the variance in the eigenvalue of that dataset (Yu et al., 1998). The pollution datasets are usually composed of climate and pollutants variables. The variables are transformed into a different set of linearly independent to find the principal components representing the original observations to identify such datasets most vital and critical driving forces. The order of PC (Principal component) has the highest variance, and it accounts for the highest driving factors of all. The consecutive PC2 and PC3 are independent of PC1, and the variance is lesser but still accounts for driving factors. The PCA was performed using the R programming language. The ambient concentration of Particulate matter and highly correlated or dependent meteorological parameters have been standardized, and the eigenvalues were calculated. The top 2 eigenvalues having the least p-value was chosen to simplify the PCs for further factor analysis.

\subsection{Factor analysis}

Factor analysis is defined as the grouping of numerous variables into single factors. The multivariable with many high correlation coefficients between the observations are grouped without losing vital information about the datasets. This analysis is usually applied to identify the best and understandable structure of the observed data and hence to find the highly significant factors which are meant to be the driving force of the fluctuations in the datasets (Buckley \& Winters, 1992). The identified factors are the product of the observed variables, which cannot be measured directly or immeasurable. The scope of the product is to minimize the variables into simple form to be explained to various policymakers (Härdle \& Simar, 2015). The factor analysis is described in Eq. 2 


$$
F_{j}=\sum_{\mathrm{i}=1}^{\mathrm{p}} \mathrm{Wji} \mathrm{Xi}=W_{j 1} X_{1}+W_{j 2} X_{2}+\cdots+W_{j p} X_{p}
$$

where $\mathrm{Fj}$ is the $\mathrm{j}^{\text {th }}$ factor, $\mathrm{W}$ is the factor number, $\mathrm{p}$ is the variables count, and $\mathrm{Xi}$ is the observed parameters. The data in the factor is a grouping of the observed data based on Eq. 2. The factor analysis was performed by initially collecting all the relevant datasets and correlation coefficients matrix between the parameters of particulate matter. Then, based on the results of the correlations, the factors loadings were determined. Finally, correlated the factors to various variables and locations/sites to identify the immeasurable parameters.

\section{Results and discussion}

The results of Spatio-temporal variations and impacts of aerosol PM during COVID-19 phase-wise lockdown conditions are presented below.

\subsection{Spatial variations}

The spatial variations of $\mathrm{AOD}$, bcAOD and $\mathrm{PM}\left(\mathrm{PM}_{2.5}\right.$ and $\left.\mathrm{PM}_{10}\right)$ patterns are shown in Figs. $1 \mathrm{a}, \mathrm{b}$ and $2 \mathrm{a}, \mathrm{b}$ respectively.

\subsubsection{AOD and bcAOD}

AOD during the pre-lockdown period (Fig. 1a) shows significant positive change by about 0.5 to 1.2 in Himalayan terrain compared to Gangetic plain, which ranges from 0 to 0.5 ; the southern peninsular regions range between -0.3 to +0.3 . After the complete lockdown, there has been a significant drop in the AOD level, extending spatially throughout India. The overall AOD decreased in the subsequent phases of lockdown (as shown in Fig. 1a). Lockdown phase I showed a significant change (reduced) over the Gangetic plain, with minimal changes in central and southern regions. Similar, insignificant changes were observed in lockdown phase II. Lockdown phases III and IV showed a clear negative change trend, showing that lockdown's impact has increased spatially. Though the unlock phase has been initiated nationwide, the pollutant concentration is generally low during the monsoon period (Ravindra et al., 2020). Hence, due to these favourable meteorological conditions, the negative change seems to be very high during this period. Usually, aerosol AOD affects atmospheric stability and precipitation as aerosols disturb the absorption of solar radiation and the scattering, hydrological cycle, and vegetation cover (Ranjan et al., 2020). However, the study shows that COVID-19 phase-wise lockdowns reduced the AOD levels across India. Similar results were also reported in other studies (Lal et al., 2020; Ranjan et al., 2020).

Spatial variability of bcAOD (Fig. 1b) shows that except for Himalayan terrain rest of the Indian regions showed a decreased change from the average period. bcAOD is highly sensitive to elevation and meteorological conditions in addition to the anthropogenic effect. Other studies further support this, showing that lockdown was not favourable in reducing air pollutants due to meteorological conditions (Wang et al., 2020b). Lower relative humidity and relatively lesser wind speed conditions hold the pollutants in the atmosphere for an extended period, contributing to higher concentration even after human travel restrictions. The conditions were improved after lockdown phase I and continued throughout the unlock phase. Hence, the impact of lockdown showed a lag but was still significantly reduced to 
a)
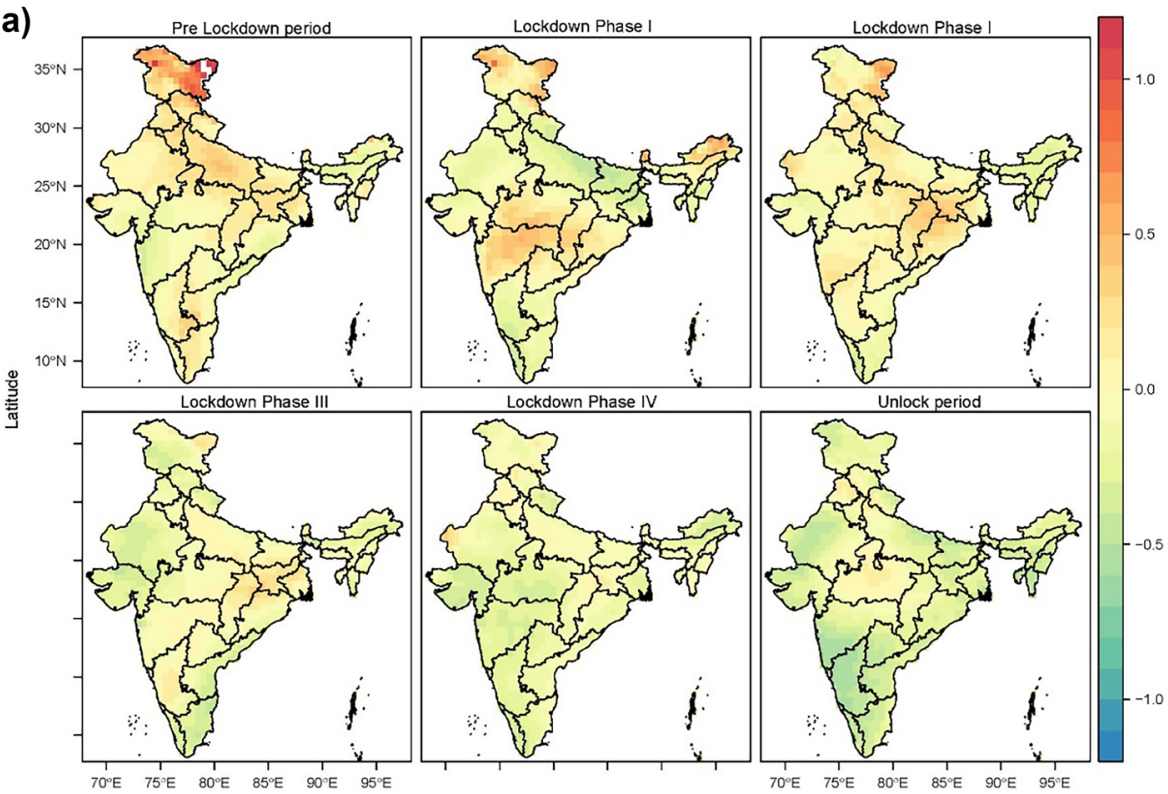

Longitude

b)
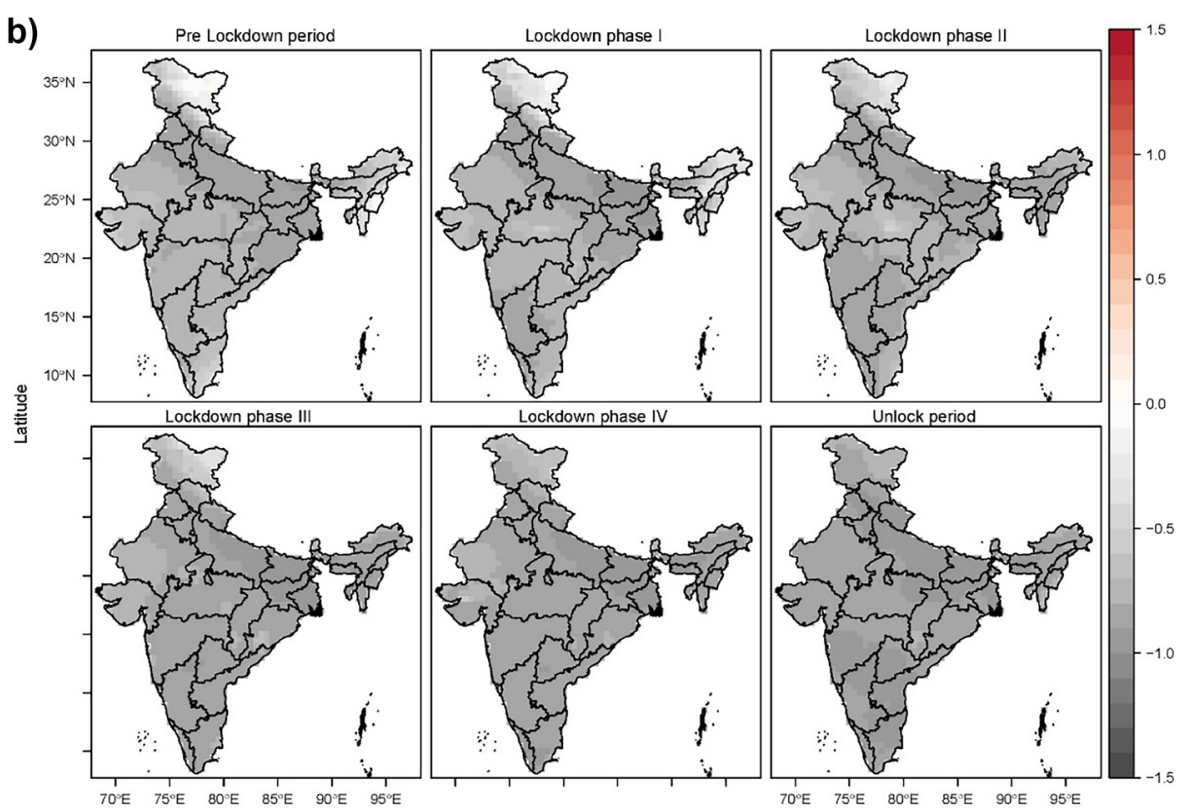

Longitude

Fig. 1 Spatial variations of a) AOD and b) bcAOD (at $550 \mathrm{~nm}$ ) over different lockdown period

about -0.13 to -0.91 . Furthermore, unlock scenario had a maximum negative change in the range of -0.68 to -0.94 . This negative change might be due to the onset of the monsoon season that accounted for $18 \%$ excess rainfall than average $(167 \mathrm{~mm})$ during the unlock phase 

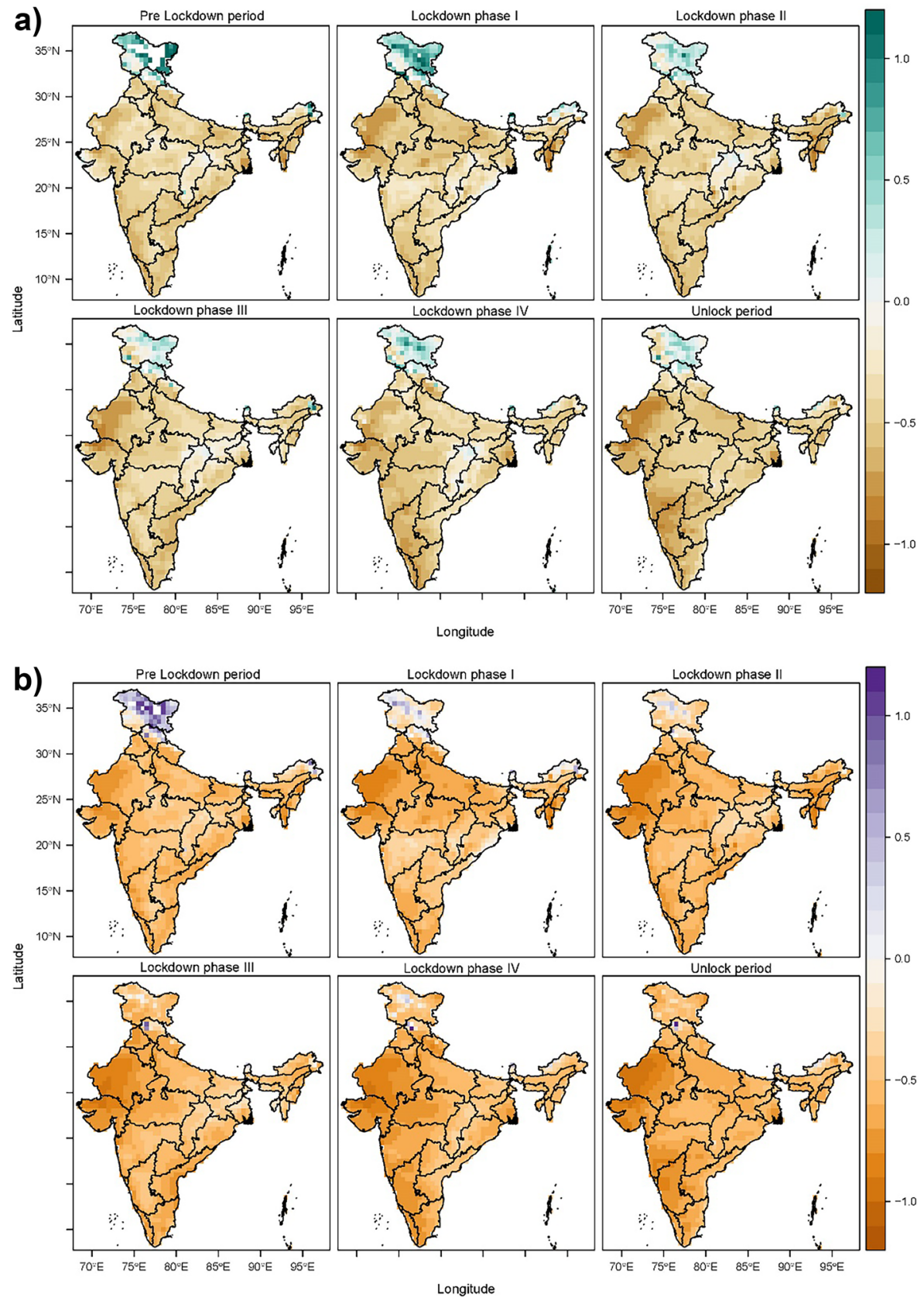

Longitude

Fig. 2 Spatial variations of a) $\mathrm{PM}_{2.5}$ and b) $\mathrm{PM}_{10}$ over different lockdown period

(IMD, 2020). This result was supported by various studies that showed a reduction in PM concentration due to the monsoon effect (Ambade et al., 2021; Guttikunda \& Gurjar, 2011; Ravindra et al., 2020). 


\subsubsection{Particulate matter $\left(\mathrm{PM}_{10}\right.$ and $\left.\mathrm{PM}_{2.5}\right)$}

The spatial patterns of particulate matter (PM10 and PM2.5) during the COVID-19 phasewise lockdowns is shown in Fig. 2a, b which revealed that both have a similar change trend and spatial pattern, as they are significantly correlated with each other. Similar to the findings of AOD, the bcAOD showed a positive change in the concentration level of PM ranging from 0 to 1.5 and in the hilly terrain of Himalayan regions. There were no changes even after the lockdown was imposed. Hence, it revealed that the lockdowns or any restrictions did not have any impact on these regions. These changes could be due to the mountains (Himalayan regions) that prevailed as a barrier for wind speed to disperse the pollutants and from very low dew point temperatures prevalence (Xu \& Zhu, 2017). However, the arid region of the country showed a relatively significant negative change in the PM level in the range of -0.9 to -0.94 . Central highlands showed insignificant changes from average value and remained in the same condition during the initial lockdown phases (pre-lockdown and lockdown phase I). In contrast, it showed a negative change in the subsequent phase of lockdown. The particulate matter ambient concentration had a positive change of PM2.5 in hilly terrain and a higher correlation with the land cover type. Similarly, the Western Ghats region also showed a more significant negative change and would have been attributed due to the monsoon (Fig. 2a, b). Overall, the metrological conditions and restrictions helped accelerate the dispersal of the concentration of PM pollutants and drastically improved air quality. The lockdown impact is visible in the middle phase of total lockdown and the unlock period in which the SWM winds helped settle and disperse the pollutants. Several source apportionment studies showed that 50-70\% of the emission of PM10 and PM2.5 are from vehicular movement (He et al., 2020; Le et al., 2020; Sarfraz et al., 2020). All the industrial activities were significantly reduced (except for essential industrial activities related to Food, Pharma, etc.) during the lockdown (Ministry of Home Affairs, 2020), which had a profound positive impact on air pollution (Nigam et al., 2021). There was a $21 \%$ reduction in PM2.5 concentration during lockdown at Almaty, Kazakhstan, with 6-34\% spatial variations compared to the average on the same days in 2018-2019. Still, it exceeded WHO daily limit values for 18 days (Kerimray et al., 2020). In Milan, Italy, the lockdown determined a significant reduction of PM10, PM2.5, BC, benzene, CO and NOx (Collivignarelli et al., 2020). Changes in air pollution levels during the lockdown measures in the city of Barcelona (NE Spain) were shown to markedly decrease but with substantial differences among pollutants, where significant reduction $\mathrm{BC}$ and NO2 (-45 to $-51 \%)$ and the lower reduction was observed for PM10 (-28 to-31.0\%) (Tobías et al., 2020).

\subsection{Temporal change}

The temporal variations in daily trends and weekly hour patterns for the significant Indian urban cities are depicted in Figs. 3 and 4.

\subsubsection{Daily change trend}

Inconsideration of the geological difference and high economic activities, the temporal analysis for the six most populated urban cities in India have been selected (three coastal and three landlocked). The change ratio for all the major six metropolitan cities significantly conveys anthropogenic impact in air pollutants over the different land 

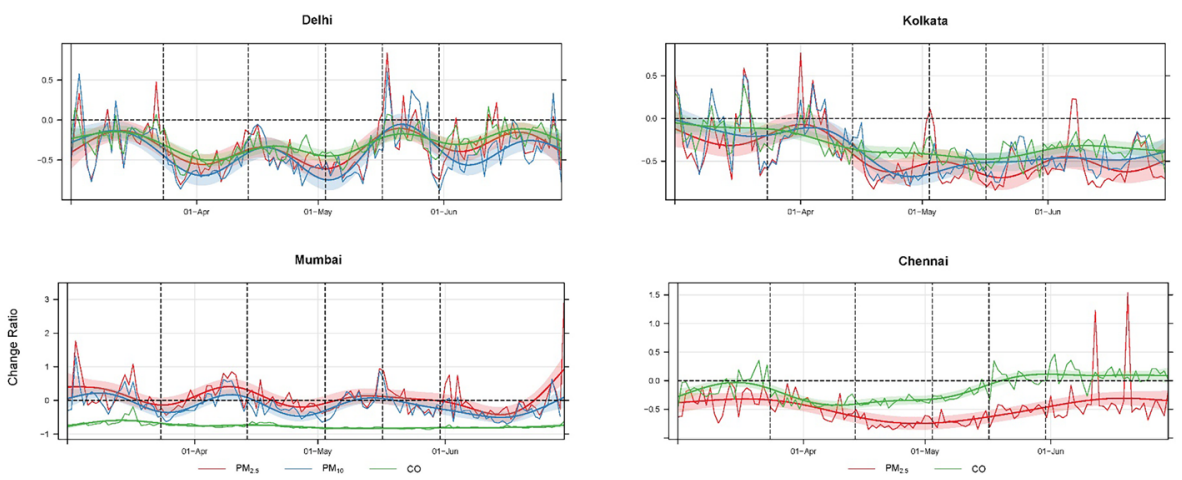

Bengaluru

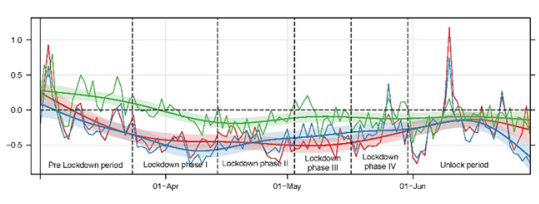

Hyderabad

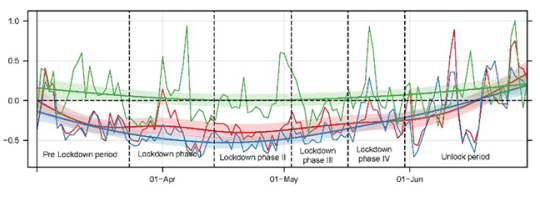

Fig. 3 Daily trend of change ratio of the air pollutants $\left(\mathrm{PM}_{10}, \mathrm{PM}_{2.5}\right.$ and $\left.\mathrm{CO}\right)$ in the most populated urban cities of India during phase-wise lockdowns

cover and climatic nature. The daily trend of change ratio of the Aerosol PM $\left(\mathrm{PM}_{10}\right.$, $\mathrm{PM}_{2.5}$ ) with $\mathrm{CO}$ addresses the vehicle movement changes in the six most populated urban cities (Delhi, Kolkata, Mumbai, Chennai, Bengaluru and Hyderabad) during phase-wise lockdowns is shown in Fig. 3. The results revealed that southern peninsular cities (Chennai, Bengaluru, Hyderabad) favoured the dispersion of pollutants due to their weather factors throughout the season except for winter. The other major cities, including Delhi, strongly depend on their meteorological factors and showed higher variability over different periods. Hence, the significant impact of restricted vehicle movement is not as visible as observed in peninsular cities. The trend in peninsular cities showed a curve structure (Fig. 3) demonstrate that movement restricted during different lockdown phases and negative change simultaneously reduced during pre-lockdown and unlock period. Delhi showed a negative change, but the difference between the lockdown and pre-lockdown were narrowed, and this could be due to unfavourable meteorological conditions prevailed. The local sources in Delhi are highly contributed by about 70-90\% (Guo et al., 2017; Sharma et al., 2018), and other studies also focused on the effect of air quality during lockdown phases in the capital city of India, Delhi (Mahato et al., 2020; Sharma et al., 2020). Another major urban city Kolkata gave a negative change trend that increased simultaneously with the prolonging time during lockdown phases and continued the increasing trend even in the unlock phase period. This occurrence is mainly due to the wind speed and direction facilitated to disperse during the entire period.

Furthermore, in Mumbai, the change ratio between the lockdown phases was narrow, varying in the range of -0.1 to 0.1 . In contrast, CR was higher during the unlock period due to higher RH in the city compared to previous years. The unfavourable meteorology in the town will significantly impact the pollutant concentrations (Sharma et al., 2020). 

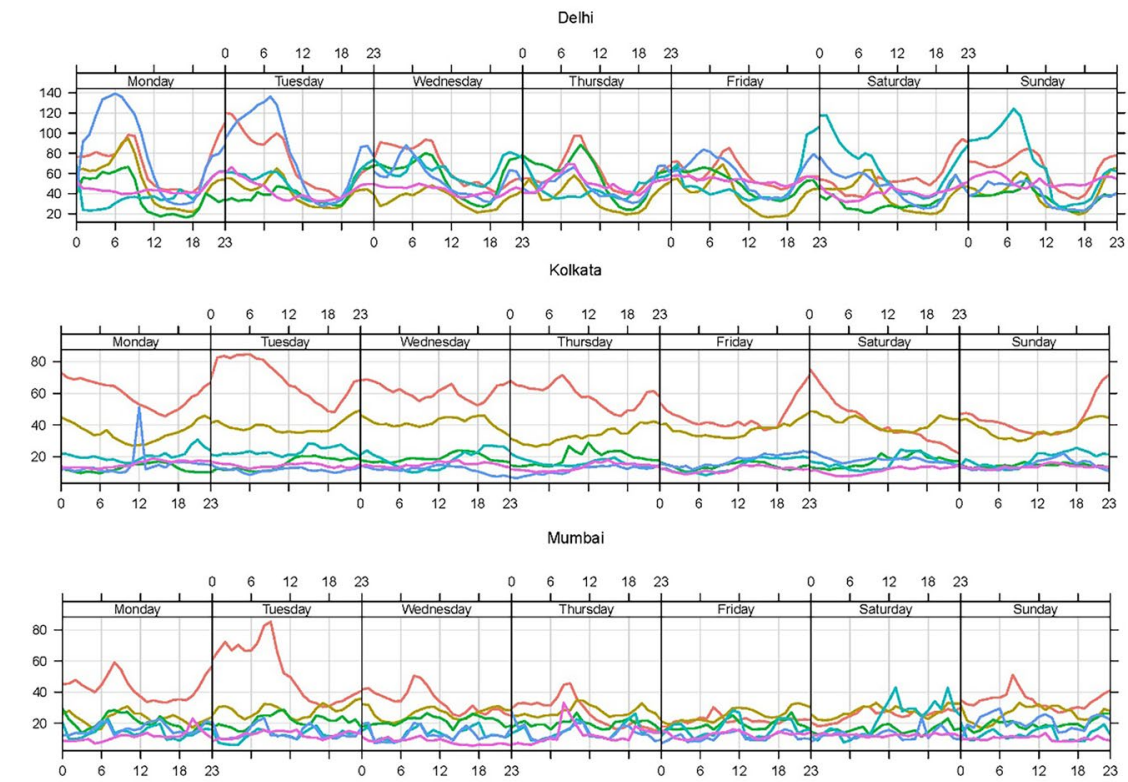

$\sum_{0}^{\infty}$
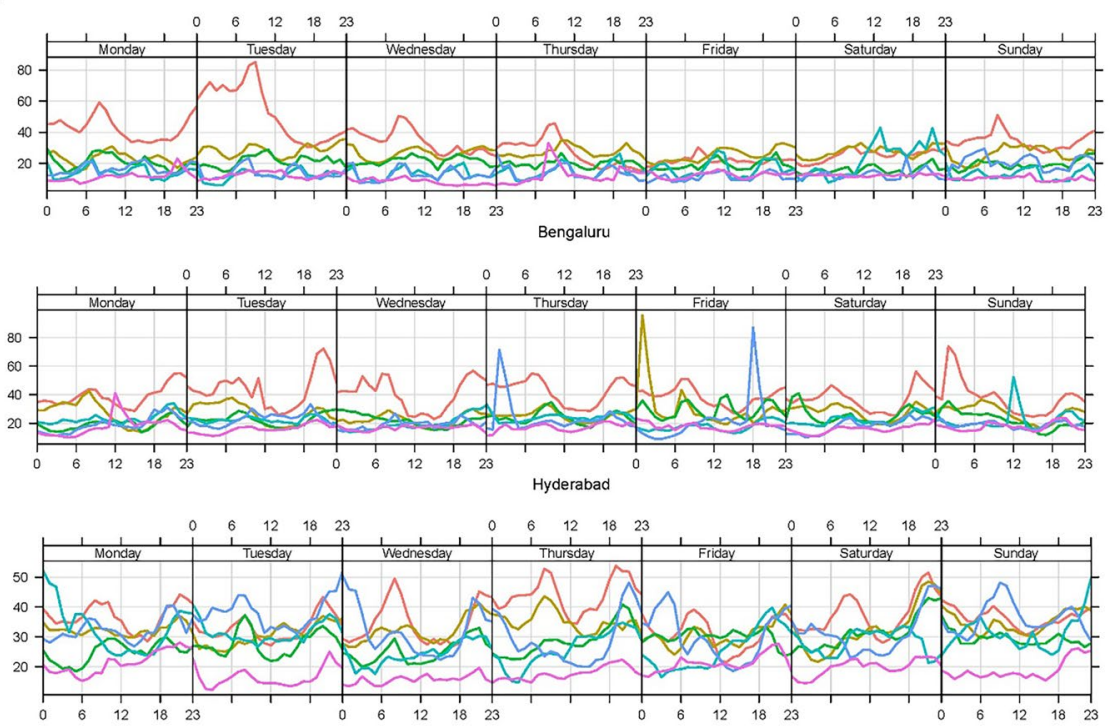

hour

Pre Lockdown period $\square$ Lockdown phase I — Lockdown phase II $\square$ Lockdown phase III $\square$ Lockdown phase IV

Unlock period

Fig. 4 Hour-weekly pattern of $\mathrm{PM}_{2.5}$ in most populated cities of India

\subsubsection{Week-hour pattern}

The week hour temporal analysis results revealed that each city follows different hourly weekly patterns based on the location with unique weather conditions during 
the various lockdown scenarios, as shown in Fig. 4. Delhi usually indicates a higher concentration in night hours than daytime hours, and a similar pattern is followed during the pre-lockdown period. The changes were significant during lockdown phases I to III and unlock period (Mahato et al., 2020). Whereas the lockdown phase IV scenario showed an insignificant difference compared to the previous lockdowns in the weather pattern and pollution load, as the restriction was relaxed during this period, it contributed to an increase in pollutant load. During unlocking time with the onset of monsoon, the peak haze/fog reduced drastically and with limited vehicle movement, the ambient concentration level of $\mathrm{PM}_{2.5}$ is at its best during this period. The monsoon could lower about 20-50\% PM concentration reported (Guttikunda \& Gurjar, 2011; Mohan $\&$ Kandya, 2007). Kolkata showed distinct variations in each phase of lockdown, and hence, a clear correlation was found towards industrial and vehicle activities. In the unlock phase, the $\mathrm{PM}_{2.5}$ concentration level was increased; however, it was under 30 to $20 \mu \mathrm{g} / \mathrm{m}^{3}$ compared to pre-lockdown (50 to $80 \mu \mathrm{g} / \mathrm{m}^{3}$ ) and lockdown (30 to $50 \mu \mathrm{g}$ / $\mathrm{m}^{3}$ ) concentrations. Mumbai followed a similar pattern to Kolkata, whereas the change difference between the lockdown phases was meagre and couldn't precisely trace the anthropogenic activities. The southern city, Chennai, ranges from 30 to $80 \mu \mathrm{g} / \mathrm{m}^{3} \mathrm{PM}_{2.5}$ concentration during the pre-lockdown phase, and vehicular movement was higher in this period than in other phases. Bengaluru also had a higher load of $\mathrm{PM}_{2.5}$ concentration due to the mobile source. Contradictorily, in Hyderabad, the variability between the different lockdown phases was higher and unable to distinguish the effect of lockdown except for the peak pattern of mobile activity. Thus, the study reveals that anthropogenic activity plays a vital role in the aerosol impact. It will be helpful for the policymakers to frame a different strategy based on the region-specific (such as the northern region of India to minimize the mobile source of pollution). Overall, the unlock phase shows the minimum ambient concentration even though the economic activities have increased. It's due to the SWM season playing a significant positive role along with associated westerlies helpful in the suspension of aerosol particles during the unlock phase period.

\subsection{Correlation analysis}

The spatial and temporal analysis showed that the Anthropogenic and Meteorological factors were the main drivers of particulate matter ambient concentration levels. It had a striking correlation between the variables in each city. Figure 5 shows the correlation between the pollutants (mobile and area source) $\mathrm{PM}_{10}, \mathrm{PM}_{2.5}, \mathrm{NO}_{\mathrm{X}}, \mathrm{CO}$ with climate parameters WS, WD, SR, RH and all the correlations were clustered using hierarchical clustering. The vehicular activities and peak hours were the same throughout the major cities, whereas the ambient concentration became accelerated and decelerated due to weather conditions and varying seasonal conditions. Vehicular and Industrial pollutants were inter-correlated with higher significance value except for Chennai, which had a higher outlier in the $\mathrm{PM}_{10}$ data. The $\mathrm{RH}$ and WS were negatively correlated factors; however, WDs were based on the different seasons. Since the lockdown phase was initiated during the summer season, the wind pattern in Chennai, Kolkata, and Delhi was positively correlated (westerly wind). In contrast, Mumbai, Bengaluru and Hyderabad had a negative correlation (easterly wind). However, during the SWM, wind direction will be reversed and thus, has an insignificant correlation with the pollutants throughout the study period. 

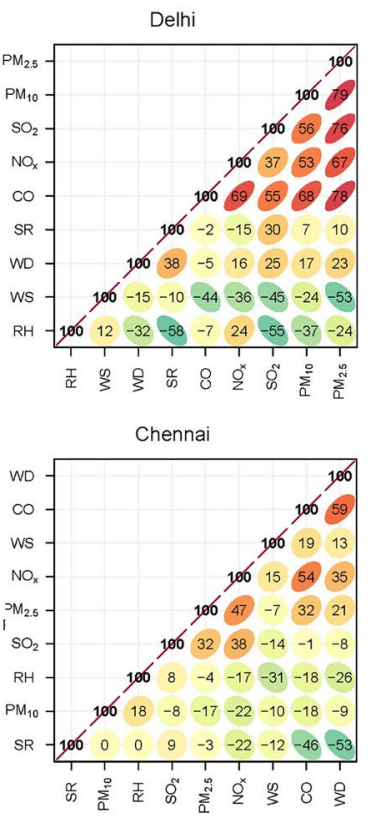

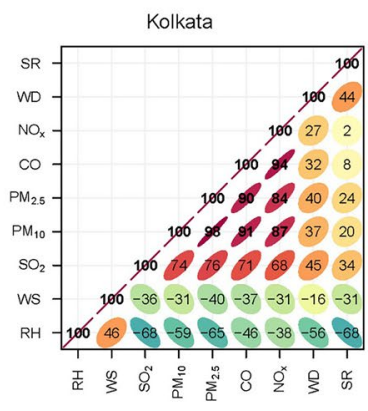

Bengaluru

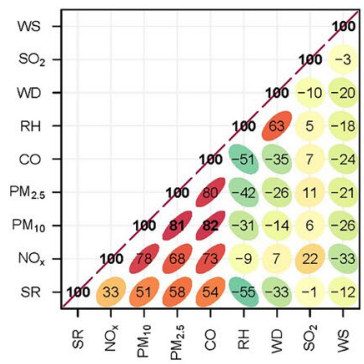

Mumbai

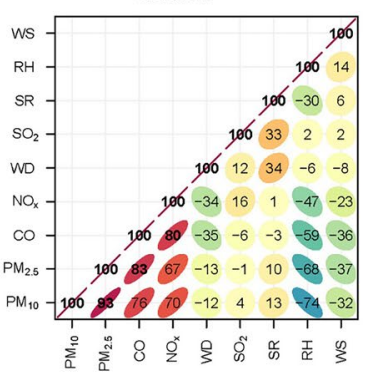

Hyderabad

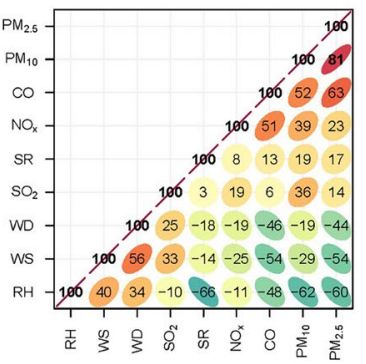

Fig. 5 Correlation and hierarchical clustering of air pollutants and climate variables in major cities of India

\subsection{PCA and factor analysis}

Principal Component with Exploratory Factor analysis was performed to simplify and qualify the factors between pollutants and weather parameters, and two apparent distinct factors with variance were found. The scale-level score for Factors was based on the cities and lockdown phases, and the outcome of the result is provided in Table 1. The anthropogenic and meteorological factors both had a significant effect on air pollutants. Figure 6 depicts the effect of anthropogenic factor relation with $\mathrm{PM}_{2.5}$ and climate variables relation with meteorological factors during phase-wise lockdowns of cities. The scatter plot between the factors showed that the first factors had a highly positive correlation with the pollutants, and thus, it was considered anthropogenic factors. The factor score is helpful to measure the movement of vehicles and other industrial activities. The anthropogenic factor score is reduced to negative in each lockdown phase, which explains the intercity comparison of human activities. This factor can be related to the lockdown phases for all the cities. The second factors were unique to different cities, and they were not related to the lockdown period. Thus, the later factor was considered to be Meteorological factors. The role of climate variables during the study period favours the lower PM concentration in southern peninsular cities, and it could be due to better relative humidity. Kolkata showed a significant increase in both RH and WD and a decrease in WS; hence the concentration of the pollutant in the daily change trend decreased in all phases of lockdown except unlock period. In Delhi, the lockdown phase IV meteorological condition were similar to pre-lockdown, and thus, PM concentration is increased. This increase in concentration might be due to relaxation in human restriction during that period. The change of WD in Mumbai is not favoured with the concentration flow during the unlock, and RH and WS remain unchanged during the study period. Hence the air pollutants with the relaxed 


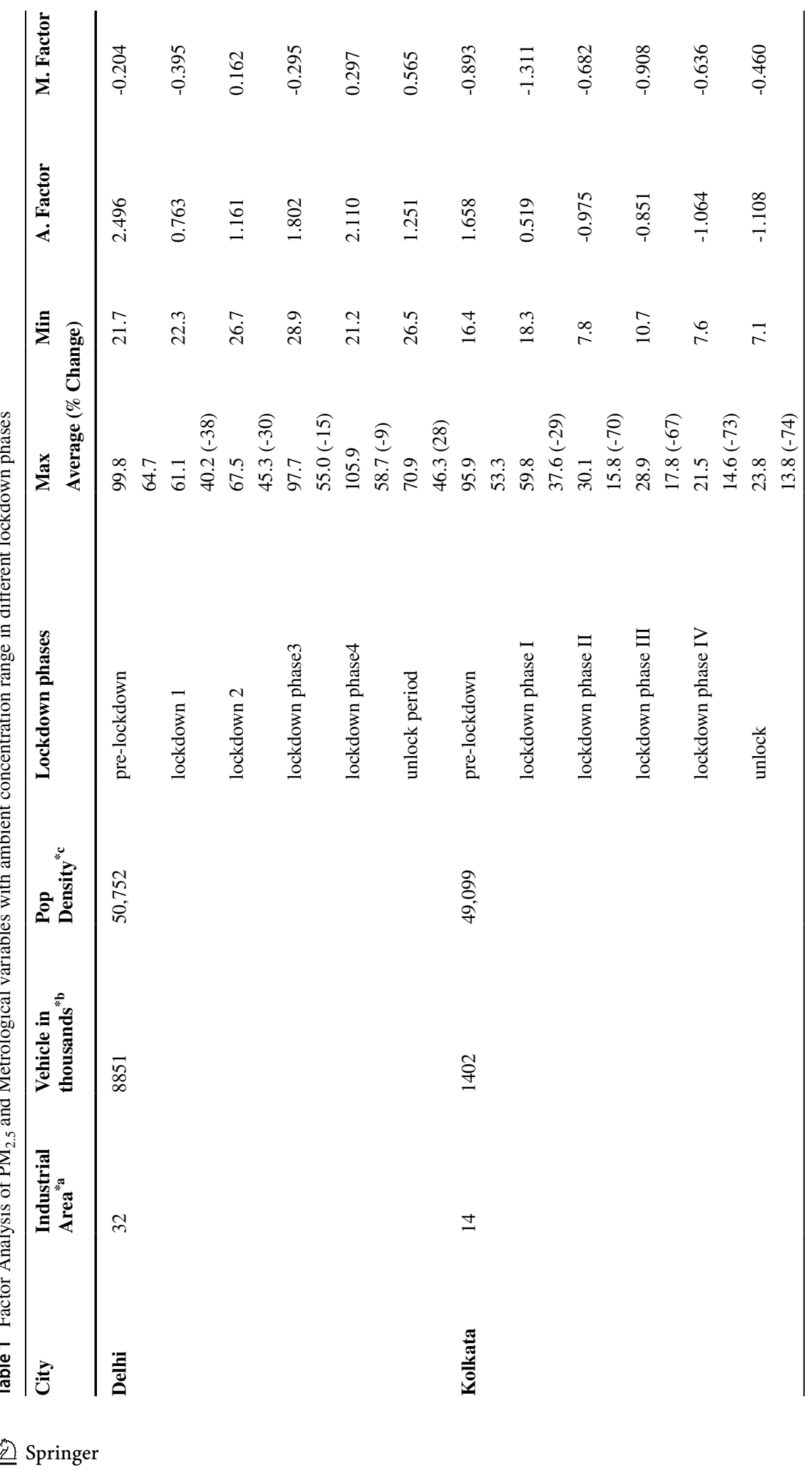




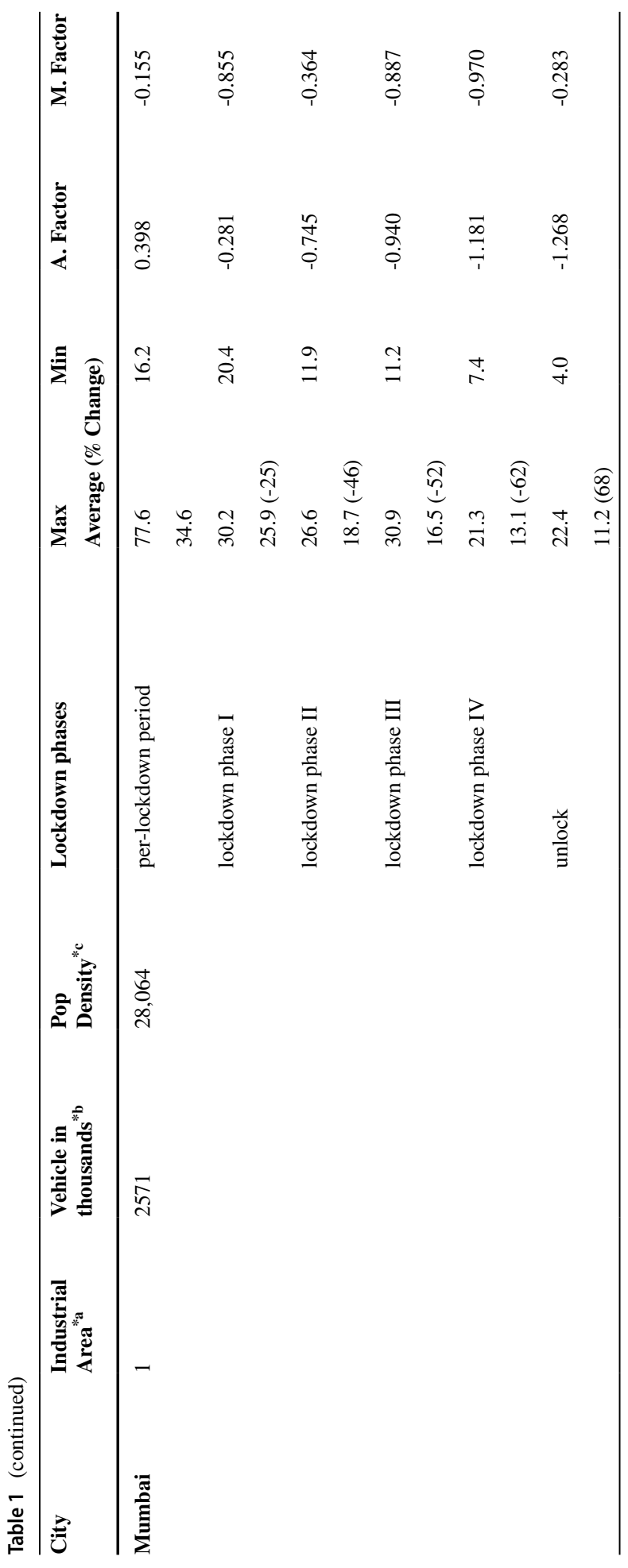




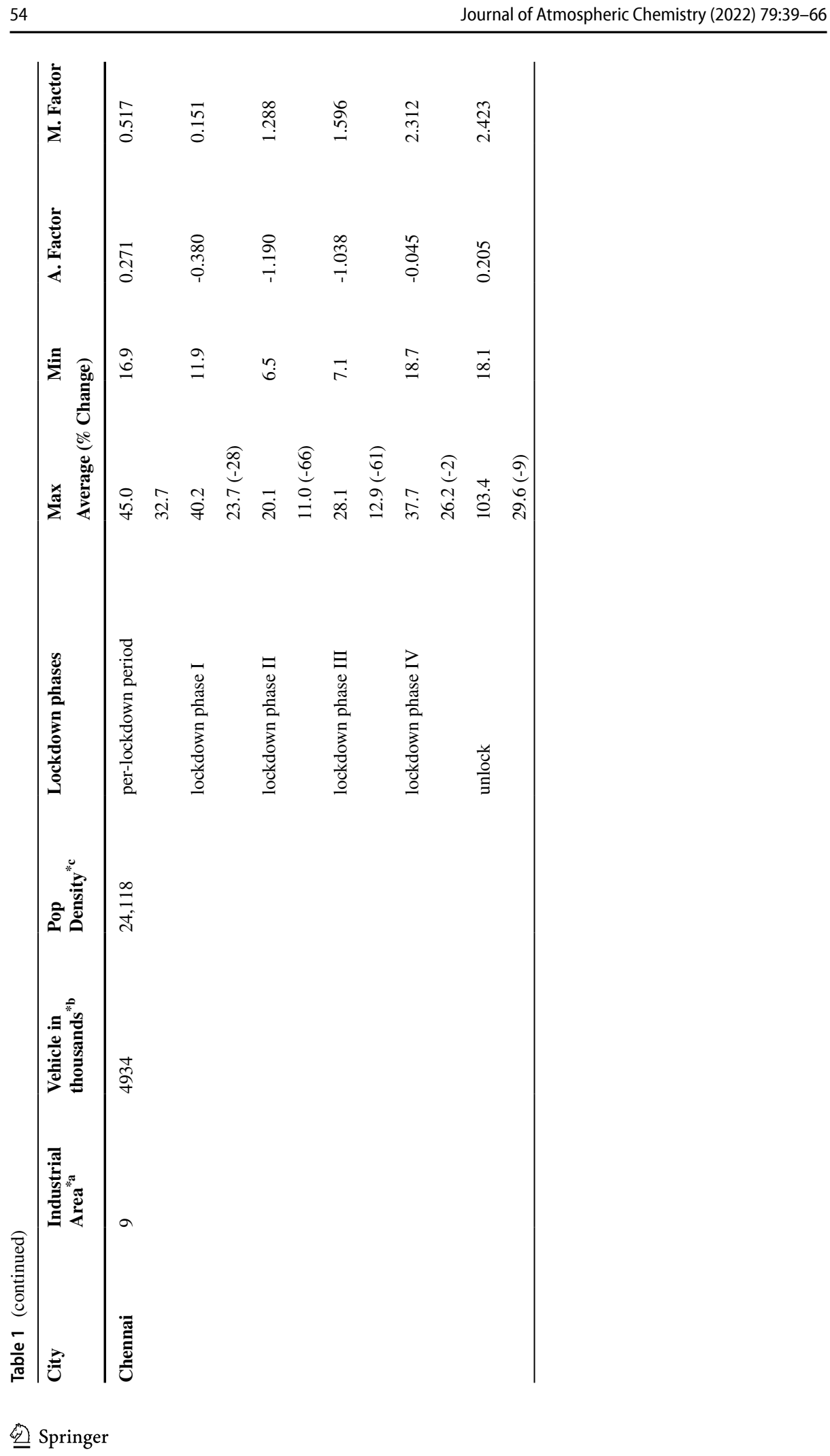




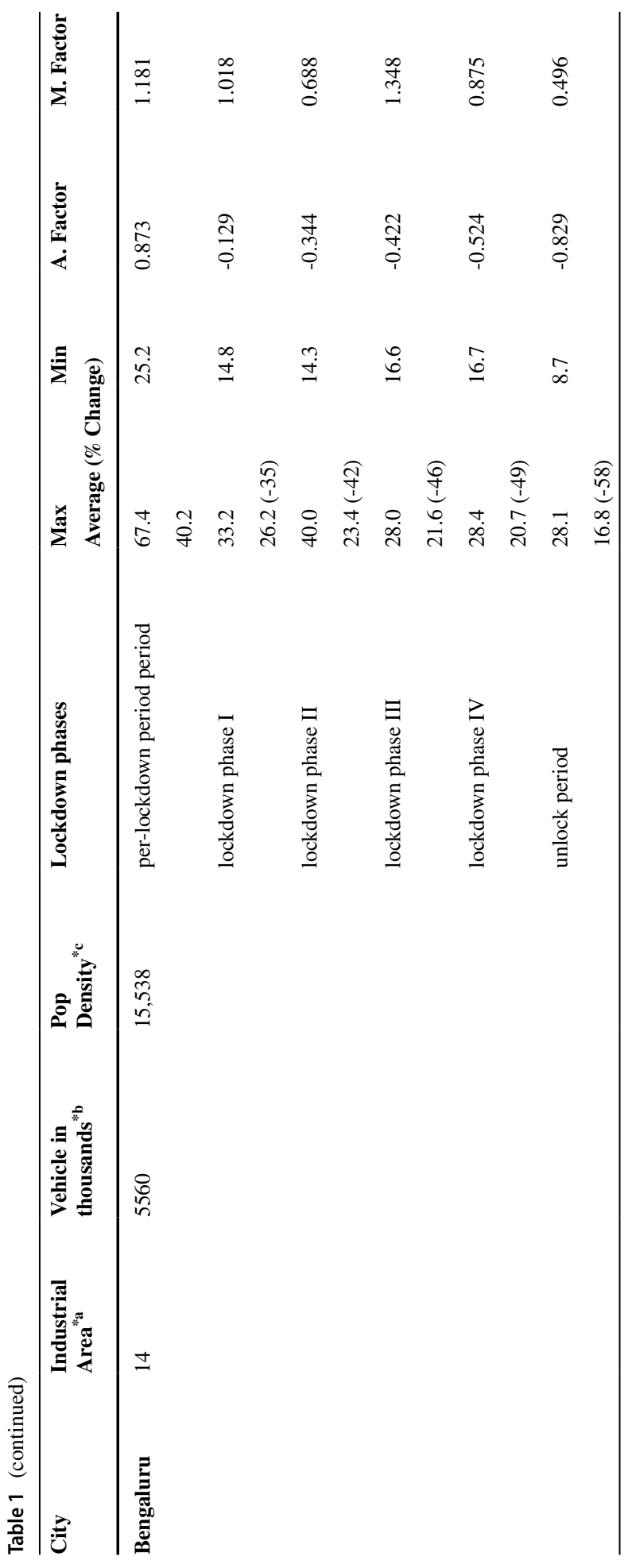




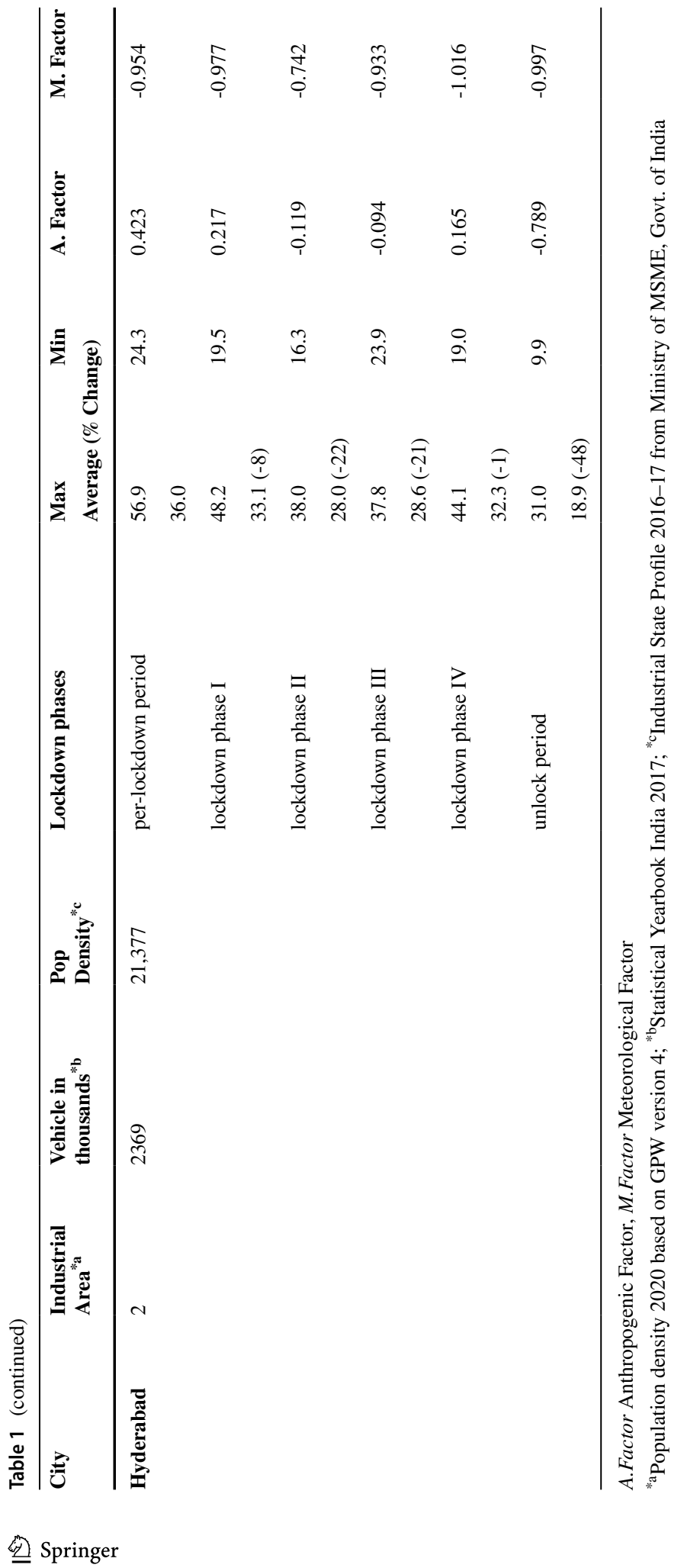



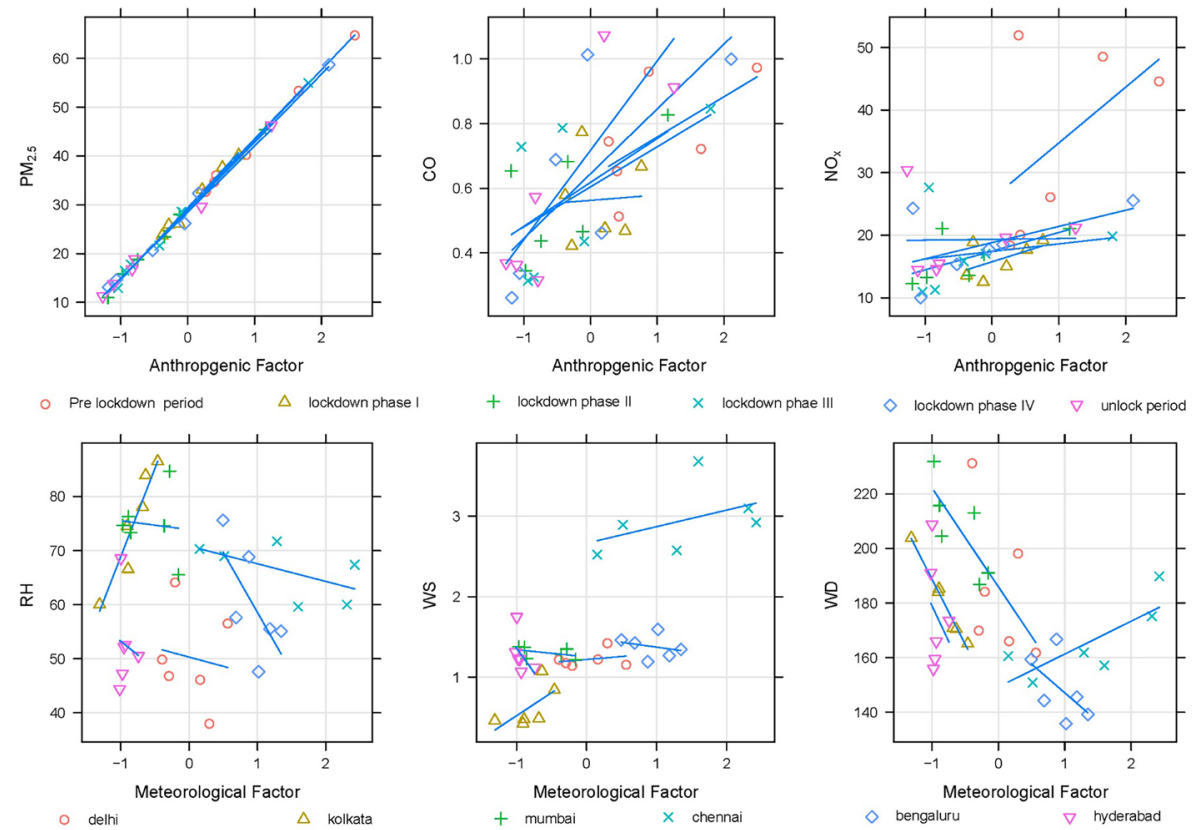

Fig. 6 Effect of Anthropogenic factor relation with pollutants to lockdowns and met relation with meteorological factor to major cities

vehicle restrictions have been masked by the unfavourable factors of weather. Chennai and Bengaluru show the insignificant impact of change in climate variables due to strict vehicle restrictions. Hyderabad has no significant relationship with Meteorological factors during the lockdown periods. Hence the southern cities have shown noticeable results in the ambient concentration level due to restrictions of non-essential activities. The Meteorological factors are vital to be considered for refining the action policies on the CAP.

\subsection{Particulate matter in the most polluted states and cities during the lockdown}

The mean pollution $\mathrm{PM}_{2.5}$ with the change from the previous years in different periods of lockdowns based on the geographical regions are listed in Table 2. All the cities are significantly influenced by the restriction in movement and show the negative change in most cities. The negative change of PM emission intensified in most cities after the lockdown was initiated and continue to maintain the low values with the benefit of SWM moist wind effect during the later period of the unlock phase. However, Delhi, Ghaziabad, Guwahati, Patna, and Varanasi exceeded the CPCB standard limit of $60 \mu \mathrm{g} / \mathrm{m}^{3}$ for $24 \mathrm{~h}$ average. The majority of highly polluted cities broadly fall under Utter Pradesh (UP), Bihar, and Kolkata, in the Gangetic plain. This might also be attributed due to their high population density (Pratap et al., 2020). A projection study of near-future $\mathrm{PM}_{2.5}$ emission based on RCP 4.5 and 8.5 scenarios shown that maximum impact is expected in Delhi (Gangetic plain) and other eastern states (Upadhyay et al., 2018). A very recent study also elucidated the health and economic impact of air pollution that correlated economic loss due to premature 


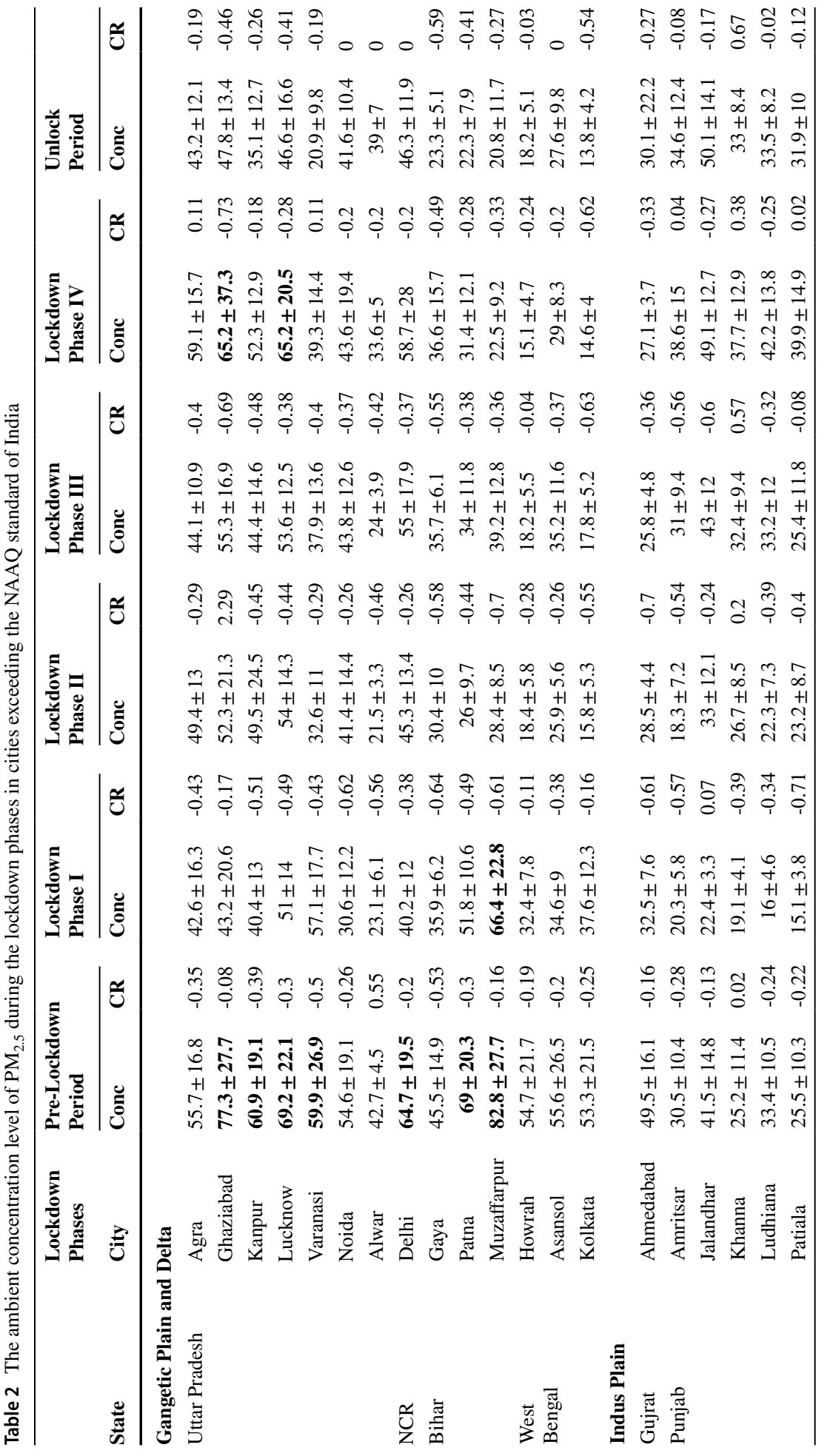




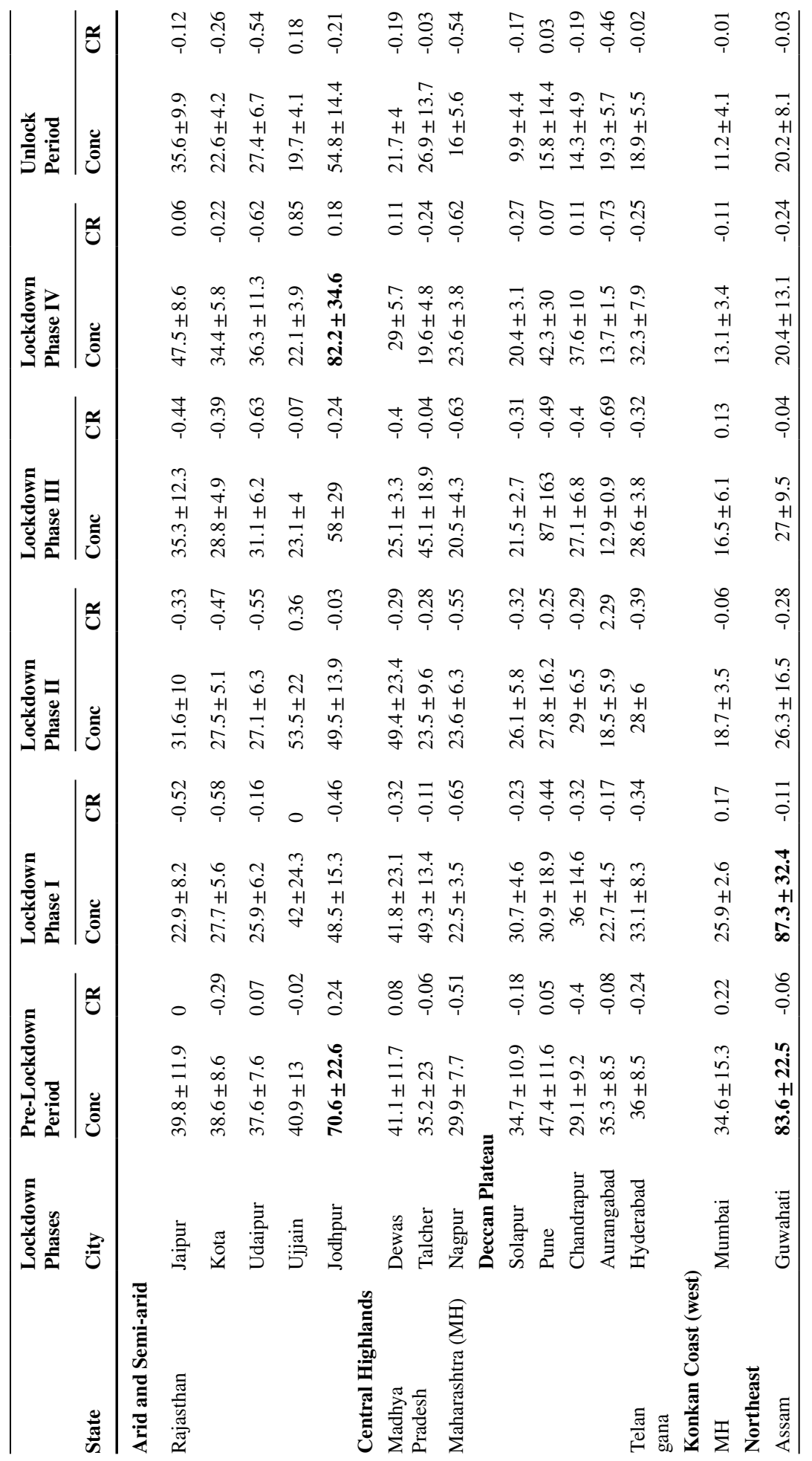




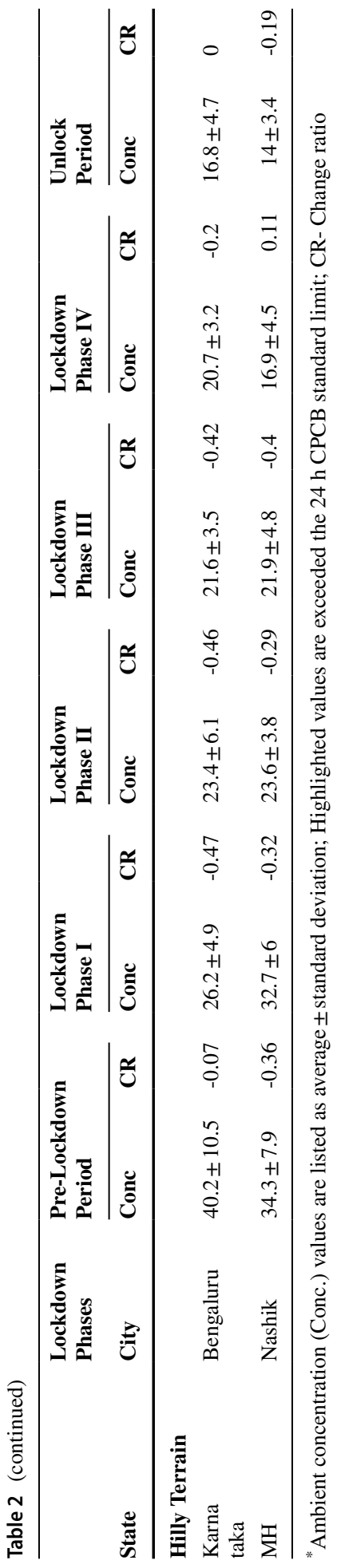

글 Springer 
deaths and morbidity attributes caused due to PM emission ranging from $0.6 \%-1.2 \%$, especially in states of Delhi, Haryana, UP, Bihar etc. (Pandey et al., 2021).

The states in the Indo-Gangetic plain region, which are most polluted, have a notable fact that biomass usage is one of the fuel sources in residential areas and lower rates of LPG migration compared to southern states of rural India (NSSO, 2015). The essential industrial activities also play as one of the point sources for such emissions. The dominance of such point sources is visible in lockdown phase III and IV phases. It increases during the summer and exceeding the threshold value of $\mathrm{PM}_{2.5}$ in Ghaziabad, Agra, and Lucknow. It is also observed that there is no significant seasonal change in WS and WD, making the cities with little carrying capacities for further developmental activities that affect the air quality. From Table 2, it is evident that the states such as UP, Bihar, Haryana, and Jharkhand falling under the Gangetic plain have an amplifiable natural factor for increasing the PM emission due to the anthropogenic activities from both mobile and point sources.

The anthropogenic activity of agricultural crop burning is also seen as one of the significant sources for PM emission, especially in the Gangetic and Indus plain in usual business activities (Jain et al., 2014). The magnitude of stubble burning could range from 40-50\% despite the movement of restriction from transport and non-essential industrial sources. It's well supported by a study that showed the deteriorating air quality of Delhi peaked about 58\% due to agriculture residue burning with fire count as high as 3000-5000 during November in Indus plain region (Beig et al., 2020). Earlier studies based on Visible Infrared Imaging Radiometer Suite (VIIRS) showed that fire count went to 30,000 in Punjab and 8000 in Haryana during the 2017-18 period (Singh et al., 2020). There could be a strong correlation between the second wave of COVID-19 cases during the post-monsoon season in Delhi and the rise of pollution due to crop burning and other favourable meteorological factors. Furthermore, the late onset of Western Disturbance during the stubble burning majorly in Punjab and Haryana states (Kanawade et al., 2020) could also be a driving factor for the decrease in air quality over the Gangetic plain (Jenamani, 2007).

\subsection{Implications of lockdown in India}

The lockdown gave stakeholders and scientists a perfect platform to distinguish the role of natural and anthropogenic factors in determining regional PM emissions. The rise of PM with no significant changes in wind and humid factors can be seen during the lockdown phase IV (May month of 2020), particularly in northern and central India. The unlock phase with the increased movement with an inverted condition of meteorological factors due to monsoon wind flow decreased the sensitivity towards PM in highly polluted states (Sharma et al., 2020). The NCAP was initiated and formulated during January 2019 to improve the air quality in India. It is a national-level response to reduce the level of air pollution and emphasis comprehensive mitigation action while also focusing on the action plan for transboundary pollution sources (NCAP, 2019). An inclusive set of directions for implementing 42 measures to mitigate air pollutions covering all emission sources for the non-attainment cities was also given in the NCAP (CPCB, 2019). Based on the current study results during the lockdown, it necessitates revamping and prioritizing the action points for different cities based on the geographical locations and various activities. Policy level recommendations based on the lockdown impact could also play a vital role in interventions by responsible agencies. An in-depth review on NCAP revealed that almost half of the action points to address the issue of transport and road dust (Ganguly et al., 2020). 
Furthermore, care should be taken for mobile source pollution by phasing out the older vehicles more significant than 15 years, encouraging green (fossil-fuel-free) mass transport, restricting heavy vehicles during peak hours, encouraging the production of e-vehicles and CNG based automobiles, etc. These steps are vital to minimize pollution, especially from the transportation sector. A systematic tracking process with adequate funding to streamline the responsible institutions based on the action points is required for effective air quality management, particularly insensitive urban locations with the least carrying capacity. The PM emission level is low during the lockdown period, as observed in this study compared to the previous business as usual years (Guttikunda et al., 2019).

\section{Conclusion}

The Spatio-temporal variations and impacts of Particulate Matter during phase-wise lockdowns in urban Indian cities were studied. The change analysis between the ambient concentration levels under lockdowns was studied from March 01 to June 30, 2020, for AOD, bcAOD, and $\mathrm{PM}_{10}$ and $\mathrm{PM}_{2.5}$. AOD and bcAOD were reduced to about 20 to $90 \%$ during lockdown phases. The Spatial change patterns of AOD and Particulate Matter showed a negative change in each phase with insignificant changes in WS, WD and RH along with the good monsoon effect. Thus, the homogeneity boundary can be framed for policymakers to define the various action plan of the clean air Programme in each region. The lockdown and ambient concentration of PM revealed that southern areas of major cities are highly influenced by mobile pollution sources than northern regions, which have poor weather patterns. Correlation and clustering analysis between the cities during the lockdown study helped map the seasonal variation between the pollutants and meteorological factors. Vehicular movement factors during the lockdown period were reduced to about 50-70\% from pre-lockdown. The most polluted cities in lockdown observed better air quality, whereas the ambient concentration level to Gangetic plain was still close to the 24-h standard limit showed the sensitivity towards climate factors. The present study categorized the Indian cities (i.e., varying geographical regions) with high to low sensitivity towards climate factors with the vehicular and industrial activities to reduce pollution load during the COVID-19 phase-wise lockdowns. These results help to frame the action plan for the clean air Programme to effectively reduce the pollutants in both the short and long term over different geographical regions of India.

Author contribution Conceptualization; Methodology; Formal analysis and investigation, Writingoriginal draft preparation: Ahamed Ibrahim. S. N, Validation, Writing-initial draft preparation and review: Sri Shalini. S, Writing - review, Funding acquisition, Project administration: Palanivelu. K, Supervision; Writing-review: Ramachandran. A

Funding Department of Science and Technology, SPLICE, Govt. of India for funding through NMSKCC Grant for Establishing/Strengthening the State Climate Change Cell and Department of Environment, Govt of Tamil Nadu and the author (Dr. S. Sri Shalini) gratefully acknowledges the financial support provided by the Department of Science and Technology (DST), Ministry of Science and Technology, Government of India under Women Scientists Scheme-A (WOS-A) (Grant no. SR/WOS-A/EA-37/2018).

Availability of data and material The data will be provided on request. 


\section{Declarations}

Conflicts of interest/Competing interests The authors declare that they have no known competing financial interests or personal relationships that could have influenced the work reported in this paper.

\section{References}

Ambade, B., Sankar, T.K., Panicker, A.S., Gautam, A.S., Gautam, S.: Characterization, seasonal variation, source apportionment and health risk assessment of black carbon over an urban region of East India. Urban Climate. 38, 100896 (2021). https://doi.org/10.1016/J.UCLIM.2021.100896

Balakrishnan, K., Dey, S., Gupta, T., Dhaliwal, R.S., Brauer, M., Cohen, A.J., Stanaway, J.D., Beig, G., Joshi, T.K., Aggarwal, A.N., Sabde, Y., Sadhu, H., Frostad, J., Causey, K., Godwin, W., Shukla, D.K., Kumar, G.A., Varghese, C.M., Muraleedharan, P., Agrawal, A., Anjana, R.M., Bhansali, A., Bhardwaj, D., Burkart, K., Cercy, K., Chakma, J.K., Chowdhury, S., Christopher, D.J., Dutta, E., Furtado, M., Ghosh, S., Ghoshal, A.G., Glenn, S.D., Guleria, R., Gupta, R., Jeemon, P., Kant, R., Kant, S., Kaur, T., Koul, P.A., Krish, V., Krishna, B., Larson, S.L., Madhipatla, K., Mahesh, P.A., Mohan, V., Mukhopadhyay, S., Mutreja, P., Naik, N., Nair, S., Nguyen, G., Odell, C.M., Pandian, J.D., Prabhakaran, D., Prabhakaran, P., Roy, A., Salvi, S., Sambandam, S., Saraf, D., Sharma, M., Shrivastava, A., Singh, V., Tandon, N., Thomas, N.J., Torre, A., Xavier, D., Yadav, G., Singh, S., Shekhar, C., Vos, T., Dandona, R., Reddy, K.S., Lim, S.S., Murray, C.J.L., Venkatesh, S., Dandona, L.: The impact of air pollution on deaths, disease burden, and life expectancy across the states of India: the Global Burden of Disease Study 2017. The Lancet Planet. Health. 3, e26-e39 (2019). https://doi.org/10.1016/S2542-5196(18)30261-4

Beig, G., Sahu, S.K., Singh, V., Tikle, S., Sobhana, S.B., Gargeva, P., Ramakrishna, K., Rathod, A., Murthy, B.S.: Objective evaluation of stubble emission of North India and quantifying its impact on air quality of Delhi. Sci. Total Environ. 709, 136126 (2020). https://doi.org/10.1016/j.scitotenv.2019.136126

Benedetti, A., Morcrette, J.J., Boucher, O., Dethof, A., Engelen, R.J., Fisher, M., Flentje, H., Huneeus, N., Jones, L., Kaiser, J.W., Kinne, S., Mangold, A., Razinger, M., Simmons, A.J., Suttie, M.: Aerosol analysis and forecast in the European Centre for Medium-Range Weather Forecasts integrated forecast system: 2. data assimilation. J. Geophys. Res. Atmos. 114, (2009). https://doi.org/10.1029/2008JD011115

Berman, J.D., Ebisu, K.: Changes in U.S. air pollution during the COVID-19 pandemic. Sci. Total Environ. 739, 139864 (2020). https://doi.org/10.1016/j.scitotenv.2020.139864

Buckley, D.E., Winters, G.V.: Geochemical characteristics of contaminated surficial sediments in Halifax Harbour: impact of waste discharge. Can. J. Earth Sci. 29(12), 2617-2639 (1992). https://doi.org/10. 1139/e92-208

Bureau of Immigration Govt of India.: Advisory:travel and visa restrictions related to COVID-19 (2020). https://boi.gov.in/content/advisory-travel-and-visa-restrictions-related-covid-19-1

Cameletti, M.: The Effect of Corona Virus Lockdown on Air Pollution: Evidence from the City of Brescia in Lombardia Region (Italy). Atmos. Environ. 239, 117794 (2020). https://doi.org/10.1016/j.atmosenv. 2020.117794

Carslaw, D.C., Ropkins, K.: Openair - An r package for air quality data analysis. Environ. Model. Softw. 27-28, 52-61 (2012). https://doi.org/10.1016/j.envsoft.2011.09.008

Collivignarelli, M.C., Abbà, A., Bertanza, G., Pedrazzani, R., Ricciardi, P., Carnevale Miino, M.: Lockdown for CoViD-2019 in Milan: What are the effects on air quality? Sci. Total Environ. 732, 139280 (2020). https://doi.org/10.1016/j.scitotenv.2020.139280

CPCB: Non Attainment Cities - City Action Plans (2019). https://cpcb.nic.in/approved-city-action-plans/

Dantas, G., Siciliano, B., França, B.B., da Silva, C.M., Arbilla, G.: The impact of COVID-19 partial lockdown on the air quality of the city of Rio de Janeiro. Brazil. Sci. Total Environ. 729, 139085 (2020). https://doi.org/10.1016/j.scitotenv.2020.139085

Ganguly, T., Selvaraj, K.L., Guttikunda, S.K.: National Clean Air Programme (NCAP) for Indian cities: Review and outlook of clean air action plans. Atmos. Environ.: X. 8, 100096 (2020). https://doi.org/10. 1016/j.aeaoa.2020.100096

Gautam, S.: COVID-19: air pollution remains low as people stay at home. Air Qual. Atmos. Health 13, 853-857 (2020). https://doi.org/10.1007/s11869-020-00842-6 
Government of India: Government of India: Ministry of Environment, Forest and Climate Change, Government launches National Clean Air Programme (NCAP) [Press release], (2019). https://pib.gov.in/ PressReleasePage.aspx?PRID $=1559384$

Guo, H., Kota, S.H., Sahu, S.K., Hu, J., Ying, Q., Gao, A., Zhang, H.: Source apportionment of PM2.5 in North India using source-oriented air quality models. Environ. Pollut. 231, 426-436 (2017). https://doi.org/10. 1016/j.envpol.2017.08.016

Guttikunda, S.K., Gurjar, B.R.: Role of meteorology in seasonality of air pollution in megacity Delhi, India. Environ. Monit. Assess. 184:5 184, 3199-3211 (2011). https://doi.org/10.1007/S10661-011-2182-8

Guttikunda, S.K., Nishadh, K.A., Jawahar, P.: Air pollution knowledge assessments (APnA) for 20 Indian cities. Urban Climate. 27, 124-141 (2019). https://doi.org/10.1016/j.uclim.2018.11.005

Härdle, W.K., Simar, L.: Applied multivariate statistical analysis, 4th edn. Springer, Berlin Heidelberg (2015)

He, G., Pan, Y., Tanaka, T.: The short-term impacts of COVID-19 lockdown on urban air pollution in China. Nature Sustainability. 1-7 (2020). https://doi.org/10.1038/s41893-020-0581-y

IMD: India Rainfall Distribution for (2020). https://mausam.imd.gov.in/imd_latest/contents/rainfallinformation. php

IQAir: World's Most Polluted Cities - PM2.5 Ranking I AirVisual. (2019). https://www.iqair.com/us/worldmost-polluted-cities

Jain, N., Bhatia, A., Pathak, H.: Emission of Air Pollutants from Crop Residue Burning in India. Aerosol Air Qual. Res. 14, 422-430 (2014). https://doi.org/10.4209/aaqr.2013.01.0031

Jain, S., Sharma, T.: Social and travel lockdown impact considering coronavirus disease (Covid-19) on air quality in megacities of india: Present benefits, future challenges and way forward. Aerosol Air Qual. Res. (2020). https://doi.org/10.4209/aaqr.2020.04.0171

Jenamani, R.K.: Alarming rise in fog and pollution causing a fall in maximum temperature over Delhi. Curr. Sci. 93, 314-322 (2007)

Jolliffe, I.T.: Principal components in regression analysis, pp. 129-155. Principal component analysis. Springer, New York, NY (1986)

Kanawade, V.P., Srivastava, A.K., Ram, K., Asmi, E., Vakkari, V., Soni, V.K., Varaprasad, V., Sarangi, C.: What caused severe air pollution episode of November 2016 in New Delhi? Atmos. Environ. 222, 117125 (2020). https://doi.org/10.1016/j.atmosenv.2019.117125

Karuppasamy, M.B., Seshachalam, S., Natesan, U. et al. Air pollution improvement and mortality rate during COVID-19 pandemic in India: global intersectional study. Air Qual. Atmos. Health 13, 1375-1384 (2020). https://doi.org/10.1007/s11869-020-00892-w

Kerimray, A., Baimatova, N., Ibragimova, O.P., Bukenov, B., Kenessov, B., Plotitsyn, P., Karaca, F.: Assessing air quality changes in large cities during COVID-19 lockdowns: The impacts of traffic-free urban conditions in Almaty. Kazakhstan. Sci. Total Environ. 730, 139179 (2020). https://doi.org/10.1016/j.scitotenv. 2020.139179

Lal, P., Kumar, A., Kumar, S., Kumari, S., Saikia, P., Dayanandan, A., Adhikari, D., Khan, M.L.: The dark cloud with a silver lining: Assessing the impact of the SARS COVID-19 pandemic on the global environment. Sci. Total Environ. 732, 139297 (2020). https://doi.org/10.1016/j.scitotenv.2020.139297

Le, T., Wang, Y., Liu, L., Yang, J., Yung, Y.L., Li, G., Seinfeld, J.H.: Unexpected air pollution with marked emission reductions during the COVID-19 outbreak in China. Science. eabb7431 (2020). https://doi.org/ 10.1126/science.abb7431

Mahato, S., Pal, S., Ghosh, K.G.: Effect of lockdown amid COVID-19 pandemic on air quality of the megacity Delhi. India. Sci. Total Environ. 730, 139086 (2020). https://doi.org/10.1016/j.scitotenv.2020.139086

Ministry of Home Affairs: Government of India: Guidelines for effective control of COVID-19: States/ UTs mandated to strictly enforce Test-Track-Treat protocol, Containment measures, COVID-Appropriate behavior and SOPs on various activities (2020). https://www.mha.gov.in/

Mohan, M., Kandya, A.: An Analysis of the Annual and Seasonal Trends of Air Quality Index of Delhi. Environ. Monit. Assess. 131:1. 131, 267-277 (2007). https://doi.org/10.1007/S10661-006-9474-4

Morcrette, J.J., Boucher, O., Jones, L., Salmond, D., Bechtold, P., Beljaars, A., Benedetti, A., Bonet, A., Kaiser, J.W., Razinger, M., Schulz, M., Serrar, S., Simmons, A.J., Sofiev, M., Suttie, M., Tompkins, A.M., Untch, A.: Aerosol analysis and forecast in the european centre for medium-range weather forecasts integrated forecast system: Forward modeling. J. Geophys. Res. Atmos. 114, (2009). https://doi. org/10.1029/2008JD011235

Muhammad, S., Long, X., Salman, M.: COVID-19 pandemic and environmental pollution: A blessing in disguise? Sci. Total Environ. 728, 138820 (2020). https://doi.org/10.1016/j.scitotenv.2020.138820

NCAP: National Clean Air Programme. Central Pollution Control Board. (2019)

NGT Order no 681.: (2018). https://greentribunal.gov.in/sites/default/files/all_documents/ ReportinOAno681 of 2018AQM.pdf 
Nigam, R., Pandya, K., Luis, A.J., Sengupta, R., Kotha, M.: Positive effects of COVID-19 lockdown on air quality of industrial cities (Ankleshwar and Vapi) of Western India. Sci. Rep. 11:1. 11, 1-12 (2021). https:// doi.org/10.1038/s41598-021-83393-9

NSSO: Energy Sources of Indian Households for Cooking and Lighting, 2011-12 Ministry of Statistics and Programme Implementation, National Sample Survey Office. (2015)

Pandey, A., Brauer, M., Cropper, M. L., Balakrishnan, K., Mathur, P., Dey, S., ... \& Dandona, L.: Health and economic impact of air pollution in the states of India: the Global Burden of Disease Study 2019. Lancet Planet. Health, 5(1), e25-e38 (2021). https://doi.org/10.1016/S2542-5196(20)30298-9

Pratap, V., Kumar, A., Tiwari, S., Kumar, P., Tripathi, A.K., Singh, A.K.: Chemical characteristics of particulate matters and their emission sources over Varanasi during winter season. J. Atmos. Chem. 77, 83-99 (2020). https://doi.org/10.1007/s10874-020-09405-6

Ranjan, A.K., Patra, A.K., Gorai, A.K.: Effect of lockdown due to SARS COVID-19 on aerosol optical depth (AOD) over urban and mining regions in India. Sci. Total Environ. 745, 141024 (2020). https://doi.org/10. 1016/j.scitotenv.2020.141024

Ravindra, K., Singh, T., Mor, S., Singh, V., Mandal, T.K., Bhatti, M.S., Gahlawat, S.K., Dhankhar, R., Mor, S., Beig, G.: Real-time monitoring of air pollutants in seven cities of North India during crop residue burning and their relationship with meteorology and transboundary movement of air. Sci. Total Environ. 690, 717-729 (2019). https://doi.org/10.1016/j.scitotenv.2019.06.216

Ravindra, K., Singh, T., Pandey, V., Mor, S.: Air pollution trend in Chandigarh city situated in Indo-Gangetic Plains: Understanding seasonality and impact of mitigation strategies. Sci. Total Environ. 729, 138717 (2020). https://doi.org/10.1016/J.SCITOTENV.2020.138717

Rodríguez-Urrego, D., Rodríguez-Urrego, L.: Air quality during the COVID-19: PM2.5 analysis in the 50 most polluted capital cities in the world. (2020)

RStudio Team: RStudio: Integrated Development for R. RStudio, PBC, Boston, MA (2020). http://www. rstudio.com/

Schulzweida, U.: CDO User Guide. (2019). https://doi.org/10.5281/ZENODO.3539275

Sharma, S.K., Mandal, T.K., Sharma, A., Saraswati, Jain, S.: Seasonal and annual trends of carbonaceous species of PM10 over a megacity Delhi, India during 2010-2017. J. Atmos. Chem. 75, 305-318 (2018). https://doi.org/10.1007/s10874-018-9379-y

Sharma, S., Zhang, M., Anshika, Gao, J., Zhang, H., Kota, S.H.: Effect of restricted emissions during COVID19 on air quality in India. Sci. Total Environ. 728, 138878 (2020). https://doi.org/10.1016/j.scitotenv.2020. 138878

Shehzad, K., Sarfraz, M., Shah, S. G. M.: The impact of COVID-19 as a necessary evil on air pollution in India during the lockdown. (2020). https://doi.org/10.1016/j.envpol.2020.115080

Singh R.P., Chauhan A.: Impact of lockdown on air quality in India during COVID-19 pandemic. Air Qual. Atmos. Health 13, 921-928 (2020). https://doi.org/10.1007/s11869-020-00863-1

Singh, T., Biswal, A., Mor, S., Ravindra, K., Singh, V., Mor, S.: A high-resolution emission inventory of air pollutants from primary crop residue burning over Northern India based on VIIRS thermal anomalies. Environ. Pollut. 266, 115132 (2020). https://doi.org/10.1016/j.envpol.2020.115132

Tobías, A., Carnerero, C., Reche, C., Massagué, J., Via, M., Minguillón, M.C., Alastuey, A., Querol, X.: Changes in air quality during the lockdown in Barcelona (Spain) one month into the SARS-CoV-2 epidemic. Sci. Total Environ. 726, 138540 (2020). https://doi.org/10.1016/j.scitotenv.2020.138540

Tobías, A., Sáez, M., Galán, I.: Herramientas gráficas para el análisis descriptivo de series temporales en la investigación médica. Med. Clin. 122, 701-706 (2004). https://doi.org/10.1016/s0025-7753(04)74361-4

Upadhyay, A., Dey, S., Goyal, P., Dash, S.K.: Projection of near-future anthropogenic PM2.5 over India using statistical approach. Atmos. Environ. 186, 178-188 (2018). https://doi.org/10.1016/j.atmosenv.2018.05. 025

Wang, C., Horby, P.W., Hayden, F.G., Gao, G.F.: A novel coronavirus outbreak of global health concern. (2020a)

Wang, P., Chen, K., Zhu, S., Wang, P., Zhang, H.: Severe air pollution events not avoided by reduced anthropogenic activities during COVID-19 outbreak. Resour. Conserv. Recycl. 158, 104814 (2020b). https://doi. org/10.1016/j.resconrec.2020.104814

WHO: WHO I Ambient air pollution: A global assessment of exposure and burden of disease (2016). https:// apps.who.int/iris/bitstream/handle/10665/250141/9789241511353-eng.pdf?sequence=1\&isAllowed=y

WHO: Coronavirus (COVID-19) events as they happen (2020a). https://www.who.int/emergencies/diseases/novelcoronavirus-2019/events-as-they-happen

WHO: WHO Coronavirus Disease (COVID-19) Dashboard I WHO Coronavirus Disease (COVID-19) Dashboard (2020b). https://covid19. who.int/gclid=EAIaIQobChMI5rOBgrP6gIVxH4rCh0HHQShEAAYA SAAEgK5_D_BwE 
Xu, Y., Zhu, X.: Recognizing Dew as an Indicator and an Improver of near-Surface Air Quality. (2017). https:// doi.org/10.1155/2017/3514743

Yu, C.C., Quinn, J.T., Dufournaud, C.M., Harrington, J.J., Rogers, P.P., Lohani, B.N.: Effective dimensionality of environmental indicators: A principal component analysis with bootstrap confidence intervals. J. Environ. Manage. 53, 101-119 (1998). https://doi.org/10.1006/jema.1998.0184

Publisher's Note Springer Nature remains neutral with regard to jurisdictional claims in published maps and institutional affiliations. 